\title{
Digital Economy and Work-from-Home: The Rise of Home Offices Amidst the COVID-19 Outbreak in India
}

\author{
Sramana Mukherjee ${ }^{1}$ D Dushyant Narang ${ }^{2}$ (D)
}

Received: 12 February 2021 / Accepted: 8 January 2022

(C) The Author(s), under exclusive licence to Springer Science+Business Media, LLC, part of Springer Nature 2022

\begin{abstract}
The coronavirus pandemic that marked its presence with the need for social distancing, mandatory self-isolations, quarantines and administrative regulatory lockdowns, has, in turn, ushered in a major transition into an all-consuming digital realm, from the physical, material world. The significance of the virtual interactions on digital platforms have increased manifold with tele-mediated interrelationships occurring at work (within the work-from-home mode), education (with stay-at-home schooling), in consumption patterns (online shopping and delivery of products) and political undertakings (such as mailed in polling). As a direct outcome, the idea of space — both physical and social - are undergoing transformations in the way they are being perceived today, more so, within the economic sectors and labour processes. Remote working in India skyrocketed under the influence of COVID-19 and set newer trends in motion making it intriguing to understand how work patterns have changed under this modus operandi. Adopting a primary survey method, conducted online, among IT sector employees of India, results have been generated across various socio-demographic categories to answer questions of efficiency and productivity, availability of infrastructure and work environment, major challenges and benefits encountered and the desired continuity of work-from-home. Through this, the study seeks to highlight whether changing work practices is leading to an overarching sense of digitality over space.
\end{abstract}

Keywords Work-from-home $\cdot$ Digital technology $\cdot$ Geography $\cdot$ Coronavirus $\cdot$ India

Sramana Mukherjee

sramana.m@rediffmail.com

Dushyant Narang

dushyantnarang@gmail.com

1 Department of Humanities and Social Sciences, National Institute of Technology, Rourkela, Odisha 769008, India

2 Embibe Individual Pvt. Ltd., Diamond District, Old Airport Road, Kodihalli, Bangalore 560008, India 


\section{Introduction}

As Sui and Morrill (2004) claimed, "No other technological innovation in human history has affected the practice of geography in such a profound way as the computer. It has drastically transformed both geography as an academic discipline and the geography of the world."

The trajectory of human civilization spans across a wide temporal scale encompassing different phases of Revolutions (starting from the Homo erectus man and his accidental discovery of fire); and the Digital Revolution is latest in that trend. With the emergence of digital technologies, characterized by their ubiquitous nature, they have taken over the mediating role of our everyday, mundane tasks such as work, travel, consumption, production and leisure. Digitality (Negroponte, 1995) becoming an aesthetic itself, captures the pervasiveness of digital technologies and shapes how we understand and experience space and spatiality as always-already 'marked by circuits of digitality' that are themselves irreducible to digital systems (Murray, 2008). As we adopt and ubiquitously embed networked digital technologies across physical landscapes, they come to enact progressively routine orderings of quotidian rhythms, interactions, opportunities, spatial configurations and flows (Franklin, 2015). What has happened in turn, is that profound effects have been generated on the nature of space and it is socio-economic, socio-cultural, socio-technical and socio-political linkages.

Consequently, as geography, from the age-old times, have been concerned with the notions of space and it is economic relations; the management and governance of places; the production of (social and physical) space, spatiality and mobilities; the processes, practices and forms of mapping; the contours of spatial knowledge and imaginaries; and the formation and enactment of spatial knowledge politics — these effect-led shifts within the contemporary digital world manages to allure geographers (Castells, 1996; Elwood \& Leszczynski, 2013; Graham \& Marvin, 2001; Rose et al., 2014; Wilson, 2012). Although geographers are not alone in this race to unravel the mysteries of the digitally-ruled, new world, rather sociologists, anthropologists, engineers, architects, planners and others - have all stepped in, bringing out many interdisciplinary perceptions (Boland Jr. et al., 2007; Alkan Meshur, 2013). But 'space' (physical, social and digital) continues to remain as an integral question within geography, within the larger technological debate, within our daily lives and also for us in this article.

Since the early 1990s, there have been a series of studies that have examined how the digital is mediating and augmenting the production of space and transforming socio-spatial relations (Afradi \& Nourian, 2020; Ash et al., 2016; Capener, 2020; Gharaghooshi et al., 2014; Mütterlein \& Fuchs, 2019). Initially, this work concentrated on how ICTs, and the internet in particular, were transforming economic, cultural, social and political geographies. Some of those work took a technologically determinist position (Dafoe, 2015), where it was assumed that networked ICTs flattened or removed the concept of distance and rendered geography irrelevant by overcoming space with time through the instantaneous transfer of information (Cairncross, 1997; Friedman, 2005; Tillema et al., 2010). However, there were others who opposed this 
view and argued that while ICTs produced space-time compression and distantiation, geography and geographical knowledge of space remained critical in our everyday lives; not denying howsoever the many shifts and transformations that the discipline underwent (Couclelis, 2009; Miller, 2017). One such transformation is seen prominently in the socio-economic arena within digital cities.

This article makes it further clearer by adopting a political-economy perspective in the analysis of the contemporary digital cities and workplaces therein. The new information economy of today is responsible for the changes in the spatial structuring of companies and employment patterns that earlier were dependent on the processes of concentration and dispersal. This, in turn, has induced significant urban-regional restructuring and the creation of a post-industrial landscape (Castells, 1996; Elwood \& Leszczynski, 2013). The industrial times were hallmarked with the industrial cities and towns (for example, London) that arose surrounding the industries and factories. The spatial structuring of these cities were so that one would find cheap labour migrating from the rural parts to live in squatter settlements, under unhygienic conditions, near the site of the industry itself; whereas, the then aristocrats were settled in the peripheral suburbs. The industry itself was located in the optimum point from its raw materials, source of power, water and even market. With the advancement of transportation and communication technologies, the premium on space as a localized focus declined over time. Workers could now commute over larger distances, raw materials could be brought in overseas and finished products could be dispersed far and wide for people's consumption. This was the era of Imperialism and India being a colony to the British Imperial Rule itself (that started with the advancement of the trading East India Company) had witnessed these socio-economic processes very closely, first hand.

As wealth and power accumulated within certain areas (geographically, the European countries were most fruitful with Britain in the lead), further advancements were continually achieved that ushered the world into the digital era - an era of 'computers and the internet'. The Digital Revolution swept in subtly and quietly, yet it brought about massive changes to this industry-led societal landscape. To start off, there was a major shift in demand and aspiration of individuals from blue collar jobs to white collar ones, and associated changes in their livelihood, quality of life and lifestyles. Society, as a whole, climbed a step higher in fulfilling the hierarchy of needs (see Maslow, 1943). Economically, this marked a complete upheaval in the concept of space-centred industries and factories, breaking them down and dispersing them far and wide, thus, paving the way for a New Division of Labour (Charnock \& Starosta, 2016) that further gave rise to the mushrooming of the multinational corporations (MNCs) in different parts of the globe. Consequently, many office activities, business services and production centres were decentralized to the suburbs, peripheral cities or other countries to take advantage of cheaper rent and labour costs (Breathnach, 2000).

These new economic trends have been further responsible for creating other socio-spatial hierarchies and creating a world completely different from that of the Industrial and Colonial times. Geographical research has highlighted how urban hierarchies today have been reinforced through the concentration of command and control, and the agglomeration of information-rich business into key places thereby 
allocating power and information in the hands of certain geographical and societal sections (such as the USA; the upper and middle class, white collar employees and so on) (Moss, 1986). This decentralized post-industrial economic landscape (see Greear, 2015), over time, further gave way to more new patterns of work that emerged under the rapidly developing ICT systems. One such pattern that we see today in great prominence, especially in the present pandemic times, is that of Remote working or the 'Work-from-Home' system.

\section{Review of Literature}

\section{'Here' or 'There': Work from Anywhere!}

The concept of "work", from the early times, has been conceptualized around activities involving physical effort for a particular purpose at a place designated for those activities (Felstead et al., 2005), and places of work were, in turn, classified according to the nature of the activities carried out there. An office, for example, is a place where administrative work is done, while a factory is a place where goods are manufactured and/or assembled. For many years, these restrictions of work to those places have been seen as given, since most work activities have not been portable. But with the emergence and advancement of technological tools like the internet, it paved the way for concepts like remote or virtual working and hence, such place-based working restrictions have been diminished in recent times.

'Working-from-home' is defined as people working from their home or from other location of their choice other than the working area by payment which is provided by the employer. It depends on teleworking/telecommunicating arrangements where an employee is not required to stay during the business hours with their colleagues and/or employer(s) (Aithal et al., 2015). However, the definition of 'telework' proposed by the International Labour Organization (ILO) in 1990 seems to be the most accepted definition that states: "A form of work in which (a) work is performed in a location remote from a central office or production facilities, thus separating the worker from personal contact with co-workers there; and (b) new technology enables this separation by facilitating communication" (Ruiz \& Walling, 2005; Beňo, 2018).

The Work-from-Home (WFH) system, or rather the remote or tele-working modus operandi, therefore, has been made possible by our ultra-connected nature of digitalized lives. Given an internet connection and the right devices (the hardware part of technology), many typical 'desk jobs' can easily be transformed and be performed from anywhere: be it in an office, at home, or even from a temporary tent-like accommodation. Similarly, Liaw et al. (2007) note, "virtual work means that employees do not need to physically go to corporate headquarters to work, but instead perform their professional jobs through internet connection from remote home, car, hotel, satellite office, or other places different from the traditional central office." Standing today, almost any job that is dependent or draws itself from technology can promote remote working. Furthermore, introduction of notebooks and cell phones made remote working a distinct possibility thereby allowing to 
work from a range of places rather than being tied to a fixed location (Felstead et al., 2005). According to Tietze (2002), work thus becomes 'disembedded' from the time/space compression and can develop into an action to be done anywhere and at any time, rather than being a place to go to. Hence, we can perceive that technology has really put the idea of 'where' under the radar in terms of the growing 'remote work culture'. With everything rapidly becoming 'e' (i.e. electronic) due to the accelerated tech-growth, 'space' is getting disrupted and digitized within the wink of an eye. Thus, the lines between 'here' and 'there' seem to be blurring rapidly.

Working from home further benefits both employees and employers, through decreased costs and increased productivity. The benefits of WFH for employees includes that they are happier working from home than in the office, provides them increased time to spend with the family, they face less stress of traveling in peak traffic hours, and the flexibility that comes with working in home contributes to their increased satisfaction (Cascio, 2000; Gibbs et al., 2021). Fu et al. (2012) found that homeworking represents a valuable energy saving option whereas Swink (2008) adds that homeworking employees may enjoy reduced expenses for work attire, less stress and reduced transportation expenses. Working from home also provides significant benefits to society, including reduced air pollution, traffic congestion and energy consumption. Taxpayer benefits include reduced costs of road maintenance and repair and a smaller demand for public transportation (Fu et al., 2012; see Curtis, 2020).

\section{Work-From-Home: 'Then' and 'Now'}

The concept of WFH came about in the early 1980s where both companies and employees were intrigued by the idea of remote working from home. It was seen as an alternative to traffic in peak hours, captivity in small cubicles and had provision of flexible working hours. A few companies allowed selected employees to WFH in an experimental mode while others debated on the lines of the potential organisational and social hazards of it. However, according to Golden (2006), at least $37 \%$ of all companies started offering WFH arrangements by then. As a global trend, estimates indicated that home-based or virtual working started becoming increasingly more popular over time especially in the UK where it had more than doubled in popularity in 8 years to 2.4 million employees working from home, and in the USA where it grew between 11 and 20\% per year, representing over 20 million employees employed in WFH. Teleworking, increasing by $11 \%$ per year, had become a highly popular way for professionals to ease ever-increasing work demands, yet still fulfil personal and family needs (Garg \& Rijst, 2015).

Consequently, flexible workspaces under the regime of WFH became a rapidly growing segment of commercial real estate across the globe. ${ }^{1}$ This small yet 'hot' segment was a veritable growth catalyst for the larger commercial real estate industry. Across the globe, these spaces were no longer just an option for businesses looking

\footnotetext{
1 Coworking Market Growth, "Coworking’s Unstoppable Market Growth”.
} 
for cost-effective, efficient, dynamic and state-of-the art physical environments for their employees. Closer to home, the demand for flexible offices — including coworking spaces and serviced offices - has grown faster in the Asia Pacific region than anywhere else (Babar, 2018), with India emerging as the second-largest market for flexible workspaces in the region (Gupta \& Virwani, 2020).

In today's time, under the current on-going pandemic of COVID-19, the blurred division of space due to WFH is more prominent, and it has generated consequent socio-economic tides that herald many transitions in both short and long term. As Gusain (2020) puts it, the accelerating remote work culture born during COVID-19 is bound to further propel the growth of flexible workspaces, especially since several employers are looking at remote working as a long-term practice. With authoritative lockdowns, social distancing norms, self-induced isolations and medically demanding quarantines, the WFH system has skyrocketed especially across the technocratic corporate world. These days, the everyday mundane rituals of getting ready for office, scrambling for the car keys, booking a cab or rushing to catch the metro, seems like a distant dream. Life as we knew it was thrown out of the window and across the globe, a new, demanding WFH culture swept in with far-reaching global technology implications, including a stepped-up demand for digital solutions.

According to a CRN Report by Steven Burke (2020), WFH has affected 265 million Americans - for better or for worse. Added to that, Burke claims that Europe is known to be feeling the cultural shock of moving to WFH more than the USA because six out of 10 people in Europe have never experienced WFH thereby making this an earth-shattering moment that has broken a cultural norm in Europe. Around 200 million people in China adopted working remotely by the end of the Chinese New Year holiday (Bick et al., 2020). India is also vividly participating in this growing global WFH trend with temporary to permanent ranging notifications of remote working from various companies, more strictly within the IT companies. 20 lakh IT employees are already known to have shifted in the WFH mode under the pandemic influence while as high as $88 \%$ of the workforce in India prefers to have the flexibility of WFH, and $69 \%$ believe their productivity has increased while working remotely, as per a survey by SAP Concur (2020), an expense management firm.

Thus, as IGEL CEO Jed Ayres puts it, "Everyone in IT across the planet is working weekends and nights to enable this massive shift to WFH. When the dust settles, we'll all be in a very different world."

\section{Technology versus Space: Is the Digital Realm Conquering the Physical Space?}

There exists a widespread debate about the convergence of computers with digital telecommunications and media technologies that has led to the creation of the "cyberspace" - a multi-media skein of digital networks which has been infusing rapidly into the social, cultural and economic life as we know it (see Graham \& Zook, 2011). Cyberspace has been defined by Batty (1993) as a "new kind of space, invisible to our direct senses, a space which might become more important than physical space itself [and which is] layered on top of, within and between the fabric of traditional geographical space". This Cyberspace, further, reflects the complex 
relations between ICT and space, place and society. Through existing binary allegations new technologies helps the society to access a new 'electronic space' or 'place', which somehow parallels the lived material spaces of human territoriality (Graham, 1998). Consequently, the question arises whether the digital realm is conquering the physical space as we know it.

The geographical effects on space based on ICT has been established, by certain scholars, to be essentialist, cause-and-effect and deterministic. The deterministic approach (see Dafoe, 2015) states that as technologies of media, computing and telecommunications converge and integrate; as equipment and transmission costs plummet to become virtually distance independent; and as broadband integrated networks start to mediate all forms of entertainment, social interaction, cultural experience, economic transaction and the labour process, distance effectively dies as a constraint on social, economic and cultural life (The Economist, 1995; see Thrift \& French, 2002). Human life becomes liberated from the constraints of space and frictional effects of distance thereby making anything possible anywhere and at any time (DuPont \& Takhteyev, 2016; Graham \& Marvin, 1996). Thus, the logic of telecommunications and electronic mediation is interpreted as inevitably supporting geographical dispersal from large metropolitan regions, or even the effective dissolution of the city itself (Gillespie, 1992; Graham, 1997). "In urban terms", writes Pawley (1995), "once time has become instantaneous, space becomes unnecessary". Furthermore, Virilio (1993), a French urban theorist and philosopher, claimed that a "culture of generalized interactivity is emerging, based on pervasive, ubiquitous and multipurpose telematics grids, through which everything arrives so quickly that departure becomes unnecessary. Such a transition will amount to nothing less than a crisis in the notion of physical dimension of space, place, the region and the city. The archaic tyranny of distances between people who have been geographically scattered increasingly gives way to the tyranny of real time".

However, the deterministic approach remains challenged by scholars propagating the social construction of technology (SCOT) approach who claim that a substitutional relationship, complex articulations emerge between interactions in geographical space and the electronic realms accessible through new technologies. Technologically determinist debates usually neglect the richness and embeddedness of human life within space as they consider the purpose of human communication to only transfer information and coordinate human activity thereby failing to appreciate the social, cultural and economic dynamics of space that cannot be simply tele-mediated irrespective of broadband, 3D, etc. Thus, the human construction of space is seen actually to ground and contextualize applications and uses of new technologies (Graham, 1998). Anchored around this idea, we have theories like actor-network by Callon $(1986,1991)$ and Latour (1993), along with Haraway's (1991) emergence of 'cyborgs'. As Thrift (1996) summarizes:

"No technology is ever found working in splendid isolation as though it is the central node in the social universe. It is linked - by the social purposes to which it is put - to humans and other technologies of different kinds. It is linked to a chain of different activities involving other technologies. And it is heavily contextualised. Thus the telephone, say, at someone's place of work had (and has) different meanings from the telephone in, say, their bedroom, and are often used in quite different ways." 
Can we then safely say that the establishment of a new world, a new socio-economic order, has already begun with the rise of digital technologies? We think we can, and in doing so, we further usher in newer trends and cultures arising from within this new order. One such fundamental trend the study highlights is 'glocalization' (see Roudometof, 2016). The concept of Glocal is a portmanteau of both 'global' and 'local' where simultaneous occurrences of global and local tendencies take place due to the reduction in distances/spaces as time takes over (Robertson, 1995). The WFH module is also known to revolutionize the traditional work culture through this embedded notion of glocalization i.e. the global (transmission of information with the help of high speed internet connectivity across different geographical locations) and the local (working from the highly localized space of home) merge together to give it a unique customisation. For instance, one employee sitting at home, with high speed internet connectivity, can connect and conduct meetings with other employees' miles away in other countries and/or other time zones. This reflects the idea of the 'space-time compression' (Harvey, 1989; Santos \& Azevedo, 2019) that is already referred to in the opening paragraphs of this article.

The growing capabilities of telecommunications, for supporting action at a distance and remote control, do not therefore negate the need for the human actors. Cyberspace emerges as a fragmented, divided and contested multiplicity of heterogeneous infrastructures and actor-networks; enrolled with human actors and other technologies into systems of sociotechnical relations across space (Graham, 1998). Consequently then, WFH system conducted mostly in the cyberspace, though a part of the larger glocal and somewhat deterministic trend is not completely outside the sociotechnical system either. Even here the idea of remote working lies governed by human actors who use the growing capabilities of telecommunications as passive agents to attain real, meaningful remote control. Although WFH replaces long distances by real-time interactions at the global level, yet on a local scale, space continues to be significant and is interwoven through the actions of human-actors.

Thus, we attempt to explore empirically how the current regime of WFH system under COVID-19 has governed these human-actors, or in this case employees, to use and impact their surrounding spaces and identify the transitions (if any) from physical spaces to the digital realm. Even though the idea of WFH/remote working/virtual working/teleworking etc. have been well explored in literature, the present study stands out in its exploration of WFH under pandemic conditions within the given digitalization trend of India. Furthermore, we try to approach and situate this study within the larger theoretical debate (technology versus space) which remains conspicuous in its absence in other existing studies.

\section{Research Design}

The current study is designed based on the above theoretical approaches to answer the problematized question of whether upcoming innovative technology makes, or has the potential to make, physical space redundant or not. With this study, we try to enter into the long standing debate of technology versus space from the point of view of recently adopted WFH system especially within the IT driven corporate sectors. What entices us within our study is the fact that whether people have completely cut themselves off 
from the physical spaces and taken their socio-economic consciousness to the digital realm thereby creating a newer form of space altogether — the digital space - or physical spaces such as office cubicles, school playgrounds and shopping areas, continue to hold significance in the daily lives of people. With WFH rendering official spaces obsolete, we direct ourselves to find out whether employees feel an urge to return back to their offices or the impromptu onset of the pandemic has been a blessing in disguise by fostering accelerated flexible workspaces and culture.

Since not all these questions can be answered through a generic theoretical understanding alone, we tried to dig deeper by undertaking a first-hand study of the people across India engaged in virtual working, especially under the influence of the global pandemic, in order to capture the ground realities empirically. Our study is broadly based on the following two objectives:

- To analyse the levels of efficiency and productivity among employees within the IT sector under WFH or remote (home-based) working system

- To construct the willingness patterns of employees in returning back to their offices post-pandemic

These objectives are further drawn upon from the pivotal research questions of this study that are designed along the lines of benefits as well as constraints of WFH modus operandi. The research questions for this study are the following:

- Does WFH or remote (home-based) working induce better efficiency and productivity among employees of IT sector?

- Will WFH induce or reduce willingness of employees to return back to designated office spaces post-pandemic?

To sum up, the given objectives strive towards answering the bigger problematized question, as mentioned above, of whether digital technology is making physical spaces redundant and in this case the well-designed, formal official spaces under the existing WFH conditions.

\section{Methodology}

The current study is exploratory in nature as it explores along the lines of the relatively new phenomenon of home-based, virtual working in India. The study is of interpretive nature drawing from its quantitative outlook as it is purely empirically situated. The empirical numbers are further backed up and contextualized under larger theoretical frameworks. A primary survey was conducted to undertake this study. The tool of data collection for the primary survey was an online questionnaire in the form of Google forms distributed among known associates. A convenience sampling method with snowballing technique was adopted in order to address the WFH employees. The primary survey yielded results in terms of 96 responses from people (or respondents) who are actively involved in WFH since the first lockdown announcement under the COVID-19 
influence in India. However, owing to the non-probability, convenience sampling methodology some nominal presence of bias comes into play along the lines of age criteria and technological know-how. The study used Microsoft Excel in order to carry out fundamental analysis of the responses received. Data pre-processing, correlations, data visualization and data interpretation were carried out on Python programming language along with libraries such as Pandas, Seaborn and Sklearn.

\section{Socio-demographic Profile of Respondents}

Out of the 96 respondents, the maximum concentration of $69 \%$ is found to be in the age group of 25-35 years followed by $28 \%$ in 15-25 years age group and a minimal of 3\% in 35-45 years age group (see Fig. 1 Distribution of respondents by age); while the gender composition is along the lines of $60 \%$ males and $40 \%$ females, with no third gender participation (see Fig. 2 Distribution of respondents by gender). The marital status is inclined towards the single category with $83 \%$ followed by $17 \%$ in the married section. Locationwise (of the respondents), the sample is divided under three broad heads — urban, semi-urban and rural with 62\%, 29\% and $9 \%$ respectively.

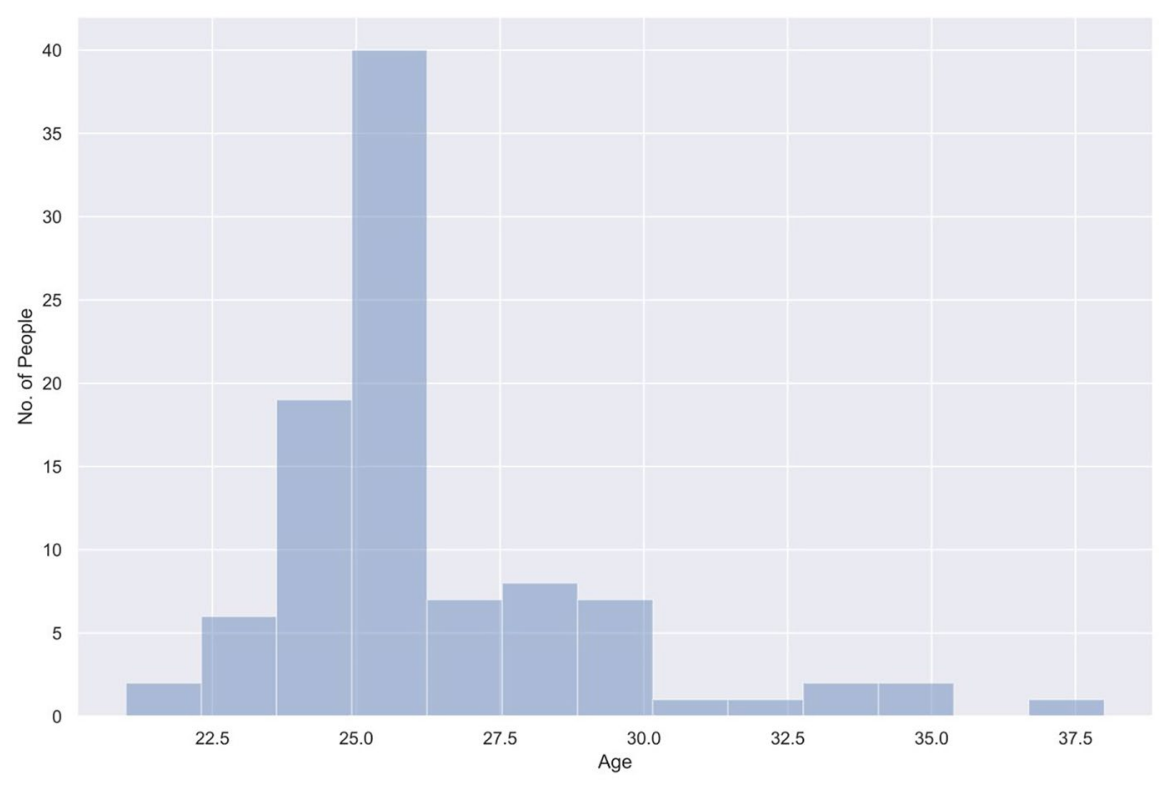

Fig. 1 Distribution of respondents by age. Source: primary data, created by authors using Python 
Fig. 2 Distribution of respondents by gender. Source: Primary data, created by authors using Python

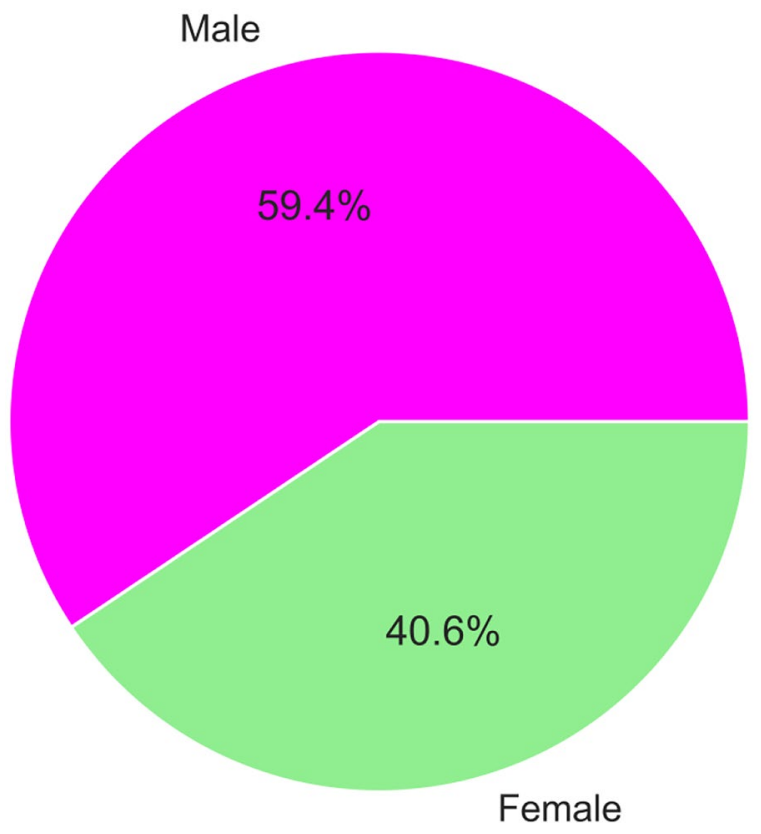

\section{Limitations}

Several limitations define the content and scope of the current study:

- Our sample remains skewed with a majority of respondents hailing from the IT corporate sector. This limits our analysis and interpretation of the true nature of WFH across different professional categories and the way people are adapting to it.

- In terms of socio-demographic variables, age of respondents tend to cluster around younger age group categories thereby eliminating senior employee' perspectives for whom WFH might have posed challenges. The sample further fails to investigate the adaptation and challenges of WFH system within a married household as there remains a preponderance of 'single' respondents. On the gender front, there is a conspicuous dearth of queer individuals.

- Our study is also limited to the time frame of the ongoing pandemic of 2020 and simulates modelled futuristic predictions rather than exploring a post-pandemic scenario.

\section{BTS of Work-From-Home}

Our behind-the-screens (BTS) analysis follows the two broad objectives of our study. Firstly, we explore how the levels of efficiency and productivity of employees of IT sector have been impacted under the WFH conditions within this COVID-19 times in India. These levels are further authenticated with the help of associative 
impacting factors like working hours, geographical location and infrastructural availability of employees. This line of our investigation remains consistent with works like Thorstensson (2020) and Aithal et al. (2015). Thorstensson, in her work, content analysed research articles published in different decades to discover the factors having an influence on the productivity of employees who work from home and the changes incurred over the years. On the other hand, Aithal et al. analysed the characteristics of WFH e-business model using 'ABCD Analysis Technique'. While the studies provide a sense of similarity, yet there remains a differing methodological approach in our work through our primary survey of employees engaged in WFH as well as a grounding in socio-geographical theories of spatiality.

Secondly, we attempt to tap into the willingness of employees towards continuity of WFH in post-pandemic times and their viewpoint on returning to offices. This idea of willingness of employees to continue WFH post-pandemic has been recently addressed by Taneja et al. (2021) in their article for the World Economic Forum. Their focus, however, have been on working adults in the UK across selected socioeconomic categories surveyed through the online mode. Senz (2020) also reflected upon similar questions on the continuity of WFH after the pandemic, against the American economic background. She further referred to the extensive work done by Stanton et al. (2020) in her article and how their survey concluded the on-going transition towards WFH as demanded by almost $16 \%$ of American workers. At the Indian context, Basu (2021) attempts to answer the question of future of WFH with the help of a Times Jobs survey titled 'How do corporates envisage year 2021?' where $1376 \mathrm{HR}$ managers working in different industrial domains and start-ups were sought out and surveyed. In her article, Basu highlights that as much as $50 \%$ of respondents claim to $\mathrm{WFH}$ in the year 2021 whereas up to $23 \%$ respondents plan to continue WFH for the next 5 years.

In our study, the focus is laid on whether employees are drawn towards the physical office spaces constructed at specific locations or does the makeshift official setup at home under remote working conditions hold a greater appeal to them. We hypothesize that if majority of employees choose to go back to offices post-pandemic, the notion of physical space retains its significance in the daily lives of people. On the other hand, if home-based flexible workspaces hold the greater appeal, the local space that is digitally connected to the global platform (a 'glocal' phenomenon) emerges as the new revolution of the contemporary economic times. This prioritizes digital space that is not restricted by physical boundaries and nullifies the idea of public spaces, commuting routes, social interactions and everyday negotiations.

\section{Levels of Efficiency and Productivity}

The most looming question about WFH today — by both employers and employees is that of impact on efficiency and productivity. In our study, majority of the respondents (54\%) felt an increase in their productivity while a mere $13 \%$ witnessed a decrease. Around $33 \%$ people claimed they felt neither increase nor decrease in their productivity levels at all under WFH. Out of the majority people who saw an increase in their productivity, $60 \%$ were males and the rest were females, and across both the categories 
there was a dominance of single or unmarried people as compared to married ones. Among the people who observed a decline in their productivity levels, $67 \%$ were men, majorly single and 33\% were women, also single. Therefore, it can be stated that more men saw an increase in their productivity levels as compared to women.

However, the point of interest here, in case of men with increased productivity, is that there is an inclination towards single men having higher productivity levels whereas women (both single and married) have attained a higher productivity level. In terms of decline, also single men had a bigger role to play than single women. The absence of married men and women under declining productivity reflects that our economic future lies in remote working as it transcends all social barriers such as gender and marital status. Productivity levels have also been impacted upon by the geographical location of the respondents. As is expected, maximum increase in productivity of people has been seen in urban and semi-urban areas followed by a meagre 5\% of respondents from rural areas. On the other hand, around 18\% and $13 \%$ people in urban and semi-urban areas felt no changes in their productivity followed by $3 \%$ from the rural areas. A negligible decline of productivity of $7 \%$ and $4 \%$ emerged from urban and semi-urban areas, respectively, while rural areas saw a negligible of $1 \%$ decline in productivity thereby giving hope for a possible digital economic future for our rural counterparts.

Furthermore, with mundane tasks such as commuting to and fro from offices being thrown out of the daily routine, the effect on the working hours of these people has undergone changes. About $71 \%$ of people confirmed that their working hours increased, $7 \%$ felt a decrease in their hours, while the remaining felt that the hours remained constant for them whatsoever. Interestingly, a gendered view of this effect on working hours of respondents (see Fig. 3 Distribution of respondents by gender, age and effect on working hours) yield that $42 \%$ male and $29 \%$ females felt an increase while $2 \%$ males and $5 \%$ females observed a dip in their working hours. Thus, overall males have exhibited an increase in their working hours under this WFH regime whereas for women although a considerable section reflected similar increased working hours, a higher number of them show declining hours as well when compared to decreased hours of men. Although in terms of statistical correlation between gender and working hours (as explored from our sample), a negative one exists stating that gender as a social factor inversely impacts on the number of hours worked under remote working conditions.

In terms of effects on the working hours and the impact of respondents' geographical location on it highlights that urban areas exhibited maximum percentage of increase in hours of people (46\%) followed by semi-urban areas (18\%). Around $11 \%$ people from urban areas and $8 \%$ from semi-urban felt that their working hours remained the same, while a minimal decrease in people's working hours of four and 3\% in urban and semi-urban areas were observed respectively. Out of our nine respondents from rural areas, majority of them witnessed a rise in their hours with none facing any decline, howsoever. One distinct pattern that arises out of this is that the major burden of operationalization of WFH falls on the urban areas and to some extent semi-urban areas; that is evident from the increased working hours as seen through our sample. However, a point to note here is that the rural areas do not lag behind either (based on our calculations). Given proper infrastructure and 


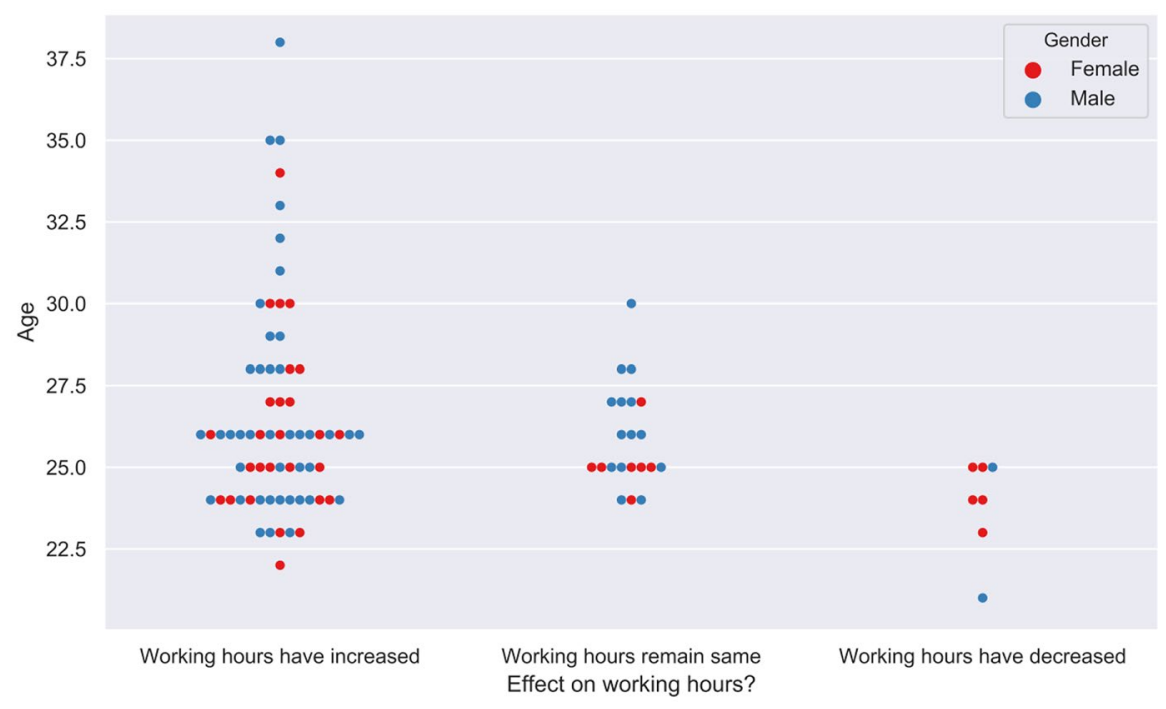

Fig. 3 Distribution of respondents by gender, age and effect on working hours. Source: primary data, created by authors using Python

equipment (continuous electricity, better network coverage, faster internet connection, speed, etc.) the culture of WFH in rural areas look like a feasible option in the upcoming future! On correlating the effect on working hours with impact on productivity responses, a deduced understanding has been made as there exists a positive correlation between them. Thus, one can say that increasing working hours has played a direct role in increasing the productivity of workers and vice versa.

Moving away from the questions of productivity and efficiency that runs parallel with working hours, another important aspect in relation to it emerged from the current study - the factor of infrastructure. In bringing our work into our homes under the contemporary WFH system, we also had to carry our offices into our living quarters. Some of us created designated spaces within our homes by setting up desks, chairs, laptops, internet modems etc., while many others found a sweet spot on the bed, snuggling with their laptop and working in their pyjamas. What is interesting to note in this, however, is that whether the organisations helped their employees by supporting them with amenities like internet connectivity, or monetary aids to buy desks and chairs and the rest? $51 \%$ of respondents claimed to have received support from their organisations in form of internet connectivity alone, while $49 \%$ have not been lucky enough to be at the receiving end for anything from their employers. The participation of employers and the organisations in the life of their employees in the form of provision of facilities helps to foster a better and smoother WFH working experience. It helps ensure that no unnecessary hiccups arise in the execution of various jobs even if done remotely from home. Many organisations believe that given the optimum environment their employees can perform further better in the globally emerging WFH system and hence, worldwide today, we see employers diverting their fiscal attention from 
bigger official infrastructures to the smaller needs of individuals of their firms working remotely.

It is such benefits of WFH that makes this modus operandi so lucrative for employees especially within the blossoming IT sector. The comfort of known home surroundings (freedom to sit anywhere and anyhow), selected aids and provisions provided suiting to the needs of individuals by their bosses, flexible working hours (one can even enjoy his/her afternoon siesta and resume work later!), and video conferencing meetings for which one does not have to dress up in their formals - are some such benefits. It is because of this reason that since March, starting when WFH was officially adopted by majority of organisations across the nation under the pandemic influence, out of our 96 respondents, 53\% have joined or have been looking for job opportunities with organisations who provide WFH benefits. All this reflects a rising sense of digitality (as theorized by Negroponte (1995)) in the daily lives of employees being achieved through means of remote working and thereby, the perception of space is undergoing changes. It reminds us of many studies theorizing the relationships between ICT networks, information flows and time-space reconfiguration that proliferated since the mid-1990s (Castells, 1996, 1997, 1998, 2001, 2009; Slevin, 2000; van Dijk, 2006). However, despite all the glamorous advantages of $\mathrm{WFH}$, it has few demerits as well that were faced by our respondents - network/internet connectivity issues, power/ electricity failures, disturbed work-life balance, technological challenges, communication gap with colleagues due to virtual mediums of communication, difficulty in tracking people and their work progress virtually, lack of physical fitness with no commuting or regular movements whatsoever, fear of salary cuts or being laid off from the workforce, lack of personal touches to assignments especially in the marketing or human resource sectors, no work related travel and opportunities to explore new cities, and specifically for women there was the added problem of juggling oneself between household chores and office commitments. Although majority faced problems of various kinds, $43 \%$ of our respondents claimed to have faced none and were highly intrigued with the WFH system.

\section{Willingness to Continue WFH}

The above analysis brings us to one of the most significant question - that of continuity of WFH system post-pandemic. Respondents were questioned regarding their preference to continue working from home or to return to the designated formal office spaces (see Fig. 4 Distribution of respondents' willingness to continue work-from-home by gender), and $41 \%$ of them were in support of continuing with WFH followed by $30 \%$ saying neither an outright yes nor a confident no. Around 29\% respondents replied in a confirmed negative and wanted to bounce back to the familiarity of those modern day economic architectural nodes known as offices. If we take up productivity levels as one of the concerning factors for continuing (or not) WFH, then a direct correlation seems to establish itself. Respondents whose productivity levels increased under WFH are positively correlated with wanting to continue with WFH while those whose productive 


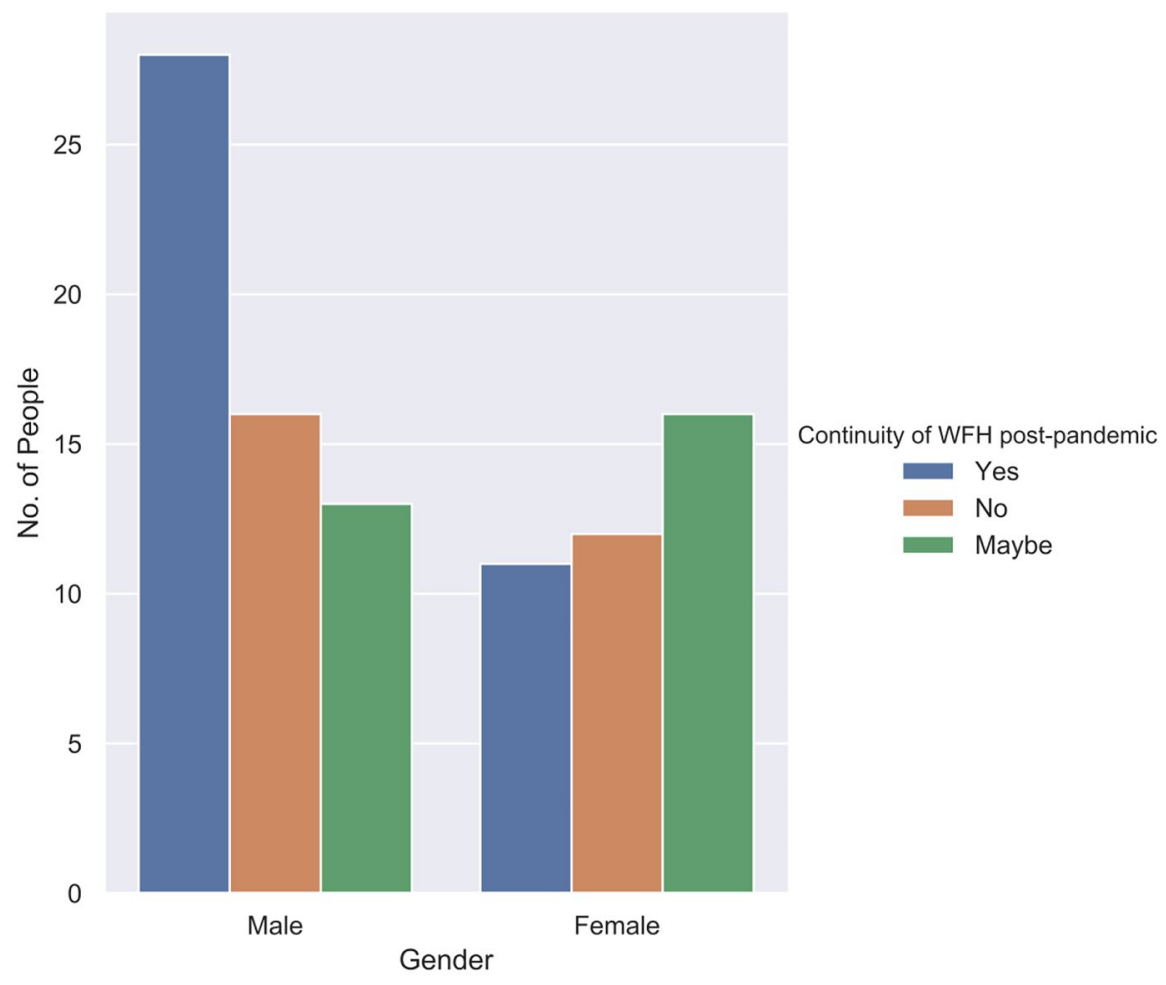

Fig. 4 Distribution of respondents' willingness to continue work-from-home by gender. Source: primary data, created by authors using Python

efficiency had a setback negatively correlated with wanting to continue with WFH. Similarly, those whose productivity saw a rise negatively correlated with wanting to go back to offices whereas people whose productive levels dropped positively correlated with wanting to go back to offices. Consequently, it can be safely interpreted that productivity remains to be an integral criteria for employees in deciding whether they want to continue WFH or would prefer to return back to their offices. On adopting a gendered lens, we see a higher percentage of males (49\%) wanting to continue with WFH as compared to females. Among those who want to return back to offices - females are in majority with $31 \%$ as compared to males. The rest of the $23 \%$ of males and surprisingly $41 \%$ of the females fall in the undecided category. The fact that women have an inclination towards going back or are undecided yet about their stand reveals a significant gender pattern of WFH mode that calls upon a more serious, in-depth research that is out of the scope of this current work.

However, we have adopted the Decision Trees algorithm (see Fig. 5 Decision tree on respondents' willingness to continue work-from-home) within the broader field of machine learning to analyse how respondents decide on whether they would like to 


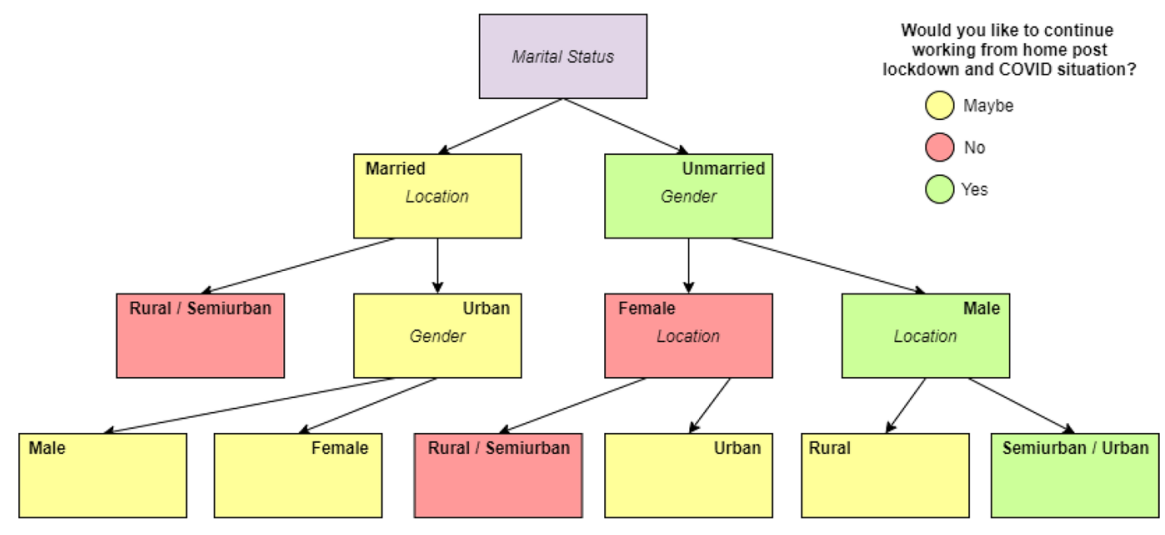

Fig. 5 Decision tree on respondents' willingness to continue work-from-home. Source: primary data, created by authors using Python

continue working from home post-lockdown and COVID situation or not based on their marital status, gender and geographical location. The tree presents marital status as the primary factor to categorize the response-, i.e.-, if a person is married his/her response will be 'may be' mostly. On the left tree, after marital status, location is considered as important parameter. On the right tree (unmarried), gender plays an important role.

\section{Discussion and Conclusion}

\section{Theoretical Implications}

With the rise of the new socio-economic order in the contemporary digital era, we see that WFH, among others, is re-conceptualizing the time-space continuum and resulting into newer patterns of time-space compression. ${ }^{2}$ Much of the space that we are acquainted with today is the digital, connected space or as Virilio (as cited by Decron, 2001) calls it 'speed-space', and we are marking our presence more with our digital footprints ${ }^{3}$ rather than in real-time or space. ICTs and the internet, in particular, have managed to transform the socio-economic, cultural and political everyday(s). From the political-economic perspective, the Digital Revolution has been the most suited ally for fostering trends of Post-Fordist manufacturing and New Divisions of Labour within the MNC culture, thereby changing the complete outlook of spatial economics. They have been aided and facilitated for smooth operation of businesses through mostly remote management and occasionally required real-time

\footnotetext{
${ }^{2}$ Harvey, D. (1989). The Condition of Postmodernity: An Enquiry into the Origins of Cultural Change. Cambridge, MA: Blackwell.

3 The information about a particular person that exists on the internet as a result of their online activity.
} 
management. The current pandemic of COVID-19 has taken all this a step further and successfully moved us on from physical engagements like days-long business trips, official meetings, and recruitment drives to virtual screens using platforms like Skype, Microsoft Teams, Zoom, and Google Meet. What occurred, in turn, was the low dependence of people on specific locations as their work sites and the rise of flexible workspaces under WFH. With flexible working hours, dispensable commuting, improved productivity and efficiency, ${ }^{4}$ the idea of WFH received stupendous popularity.

\section{Managerial Implications}

In our explorations, as mentioned earlier, we tried to internalize this basic yet vital juxtaposition of (digital) technology and (physical) space as studied through the lens of pandemic-inflicted WFH in India. With a higher percentage of respondents opinionated towards continuing WFH even in post-pandemic times, a distinct inclination was seen towards digitally connected spaces over socially run physical ones. Employees are more than willing to hold onto their comfortable 'local-scapes' at home while connecting with outer world via their online screens. Moreover, majority of our sample respondents, around 54\%, faced an increase in their productivity and efficiency levels that further supported their decision of WFH and its continuity even in post-pandemic era. However, with deeper introspections on this subject matter, though it can be proclaimed that technology has directed its strides towards dismissing the idea of physical spaces to a great extent and consciously or unconsciously we have shifted our loci into a newer kind of space - the digital space; yet, the process in its entirety remains incomplete. Even with the skyrocketed rise of digital spaces, the operationalization and functioning of physical spaces have only evolved to suit and adapt to the contemporary digital times rather than becoming obsolete. Today, physical and digital spaces coexist together and are co-opted in everyday lives. At the work front, the $29 \%$ of our sample population who staunchly denied continuing WFH reflect that section of the society which still enjoys the benefits of physical (official) spaces with balanced incorporation of technical aids.

Added to this, WFH is also known to be responsible for the complete breakdown of the already existing work culture and structure. For those without the means of fast internet connections, functioning laptops/computers and other required digital infrastructures, the on-going WFH drive is proving to be a huge challenge. The office culture that existed even until 2019 has come to a complete standstill under lockdowns, quarantines and mandatory WFH routines. According to an article by BBC published in August 2020, it claims that city centres could become 'ghost towns,' if the workers chose not return to offices. Although allowing staff to work from home had helped keep firms afloat during the pandemic but as offices stand empty, thousands of local businesses that relied on the passing

\footnotetext{
${ }^{4}$ As presented within our study where majority of respondents felt a surge in their overall efficiency and productivity levels.
} 
trade are suffering not to mention millions worth of infrastructure lying idle. Thus, even with all its added benefits - for both employers and employees - there continues to exist challenges with WFH. Consequently, even though technology has a really strong ballgame going on, but it is not enough to make physical, and within it the deep embedded social spaces, redundant. What it has actually achieved is an amalgamation of both physical and digital spaces and a digitally-connected yet physically-rooted local home space (glocal in nature) created under Work-fromHome system in these pandemic times! It is with more time that we will know for sure the direction in which our future is headed. Till then, let the debates of 'space' and 'technology' be carried on!

Author Contribution The authors confirm that they have made substantial contributions to the conception, data collection and analysis, data interpretation and overall execution of this work. It has further been revised carefully and approved of before submitting for publication to the journal. The authors declare that the work is original. It has not been published elsewhere, nor is it currently under consideration for publication elsewhere. The authors also agree to be accountable for all aspects of the work.

Availability of Data and Material Both authors agree that all the data and material support the claims and interpretation made within the article and comply with field standards.

Code Availability The authors agree that the code used support the claims within the article and comply with field standards.

\section{Declarations}

Ethics Approval Not applicable.

Consent to Participate The authors declare that all the respondents had willingly participated in the online survey conducted for this study.

Consent for Publication Both authors agreed with the content and gave consent to submit the manuscript to the journal publishing house for publication.

Conflict of Interest The authors declare no competing interests.

\section{References}

Afradi, K., \& Nourian, F. (2020). Understanding ICT's impacts on urban spaces: A qualitative content analysis of literature. GeoJournal, 85(4).

Aithal, P. S., Reshma, V. T. S., \& Acharya, P. S. (2015). An empirical study on working from home: A popular e-business model. International Journal of Advance and Innovative Research, 2(2), $12-18$.

Alkan Meshur, H. F. L. (2013). Planners' attitudes toward the spatial impacts of information and communication technologies. Gazi University Journal of Science, 26(3), 473-487.

Ash, J., Kitchin, R., \& Leszczynski, A. (2016). Digital turn digital geographies? Progress in Human Geography, 42(1), 25-43.

Babar, K. (2018). Over 13 million people estimated to operate out of co-working spaces in India by 2020. News article by Report ET RealEstate. https://realty.economictimes.indiatimes.com/news/ commercial/over-13-million-people-estimated-to-operate-out-of-co-working-spaces-in-india-by2020-report/64388830 
Basu, S. (2021). Work from home to be new normal in 2021 too, HR managers keen on hiring - TimesJobs survey. News article by ET Bureau - The Economic Times. https://economictimes.indiatimes. $\mathrm{com} /$ news/company/corporate-trends/work-from-home-to-be-new-normal-in-2021-too-hrmanagers-keen-on-hiring-timesjobs-survey/articleshow/80155956.cms

Batty, M. (1993). The geography of cyberspace. Environment and Planning b: Planning and Design, 20, $615-661$.

Ben̆o, M. (2018). Working in the Virtual World - an Approach to the "Home Office" Business Model Analysis. Ad Alta: Journal of Interdisciplinary Research, 8(1), 25-36.

Bick, R., Chang, M., Wang, K. W., \& Yu, T. (2020). A blueprint for remote working: Lessons from China. McKinsey Digital Report. https://www.mckinsey.com/business-functions/mckinsey-digital/ our-insights/a-blueprint-for-remote-working-lessons-from-china

Boland, R. J., Jr., Lyytinen, K., \& Yoo, Y. (2007). Wakes of innovation in project networks: The case of digital 3-D representations in architecture engineering and construction. Organization Science, 18(4), 631-647.

Breathnach, P. (2000). Globalisation information technology and the emergence of niche transnational cities: The growth of the call centre sector in Dublin. Geoforum, 31, 477-485.

Burke, S. (2020). Coronavirus is creating a global 'work-at-home' culture. CRN. Accessed on October 20 from www.crn.com/news/cloud/coronavirus-is-creating-a-global-work-at-home-culture

Cairncross, F. (1997). The death of distance. Orion Business Books.

Callon, M. (1986). Some elements of a sociology of translation: Domestication of the scallops and the fisherman of St Brieuc bay. In J. Law (Ed.), Power action and belief: A new sociology of knowledge (pp. 196-232). Routledge.

Callon, M. (1991). Techno-economic networks and irreversibility. In J. Law (Ed.), A sociology of monsters: Essays on power technology and domination (pp. 196-232). Routledge.

Capener, D. (2020). The magic and metaphysics of shit: The production of space and digital technology. Architecture and Culture, 8(3-4), 636-652.

Cascio, W. F. (2000). Managing a virtual workplace. The Academy of Management Executive, 13(3), 81-90.

Castells, M. (1996). The information age:Economy society and culture volume I: The rise of the network society. Oxford: Blackwell.

Castells, M. (1997). The information age:Economy society and culture volume II: The power of identity. Oxford: Blackwell.

Castells, M. (1998). The information age:Economy society and culture volume III: End of millennium. Oxford: Blackwell.

Castells, M. (2001). The internet galaxy: Reflections on the internet business and society. Oxford University Press.

Castells, M. (2009). Communication Power. Oxford University Press.

Charnock, G., \& Starosta, G. (2016). Introduction: The new international division of labour and the critique of political economy today. In G. Charnock, et al. (Eds.), The new international division of labour (pp. 1-22). Palgrave Macmillan.

Couclelis, H. (2009). Rethinking time geography in the information age. Environment and Planning A, 41(7), 1556-1575.

Curtis, M. (2020). (re)Awakening to the benefits and climate impacts of telework during COVID-19. UC San Diego: Climate Science and Policy. Retrieved from https://escholarship.org/uc/item/7nf8k2q6

Dafoe, A. (2015). On technological determinism: A typology scope conditions and a mechanism. Science Technology \& Human Values, 40(6), 1047-1076.

Decron, C. (2001). Speed-space. In J. Armitage (Ed.), Virilio Live (pp. 69-81). Sage.

DuPont, Q., \& Takhteyev, Y. (2016). Ordering space: Alternative views of ICT and geography. First Monday, 21(8).

Elwood, S., \& Leszczynski, A. (2013). New spatial media new knowledge politics. Transactions of the Institute of British Geographers, 38, 544-559.

Felstead, A., Jewson, N., \& Walters, S. (2005). The shifting locations of work: New statistical evidence on the spaces and places of employment. Work Employment and Society, 19(2), 415-431.

Franklin, S. (2015). Control: Digitality as Cultural Logic. Cambridge, MA: MIT Press.

Friedman, T. (2005). The world is flat: A brief history of the twenty-first century. Farrar Straus and Giroux. 
Fu, M., Kelly, J. A., Clinch, J. P., \& King, F. (2012). Environmental policy implications of working from home: Modelling the impacts of land-use infrastructure and socio-demographics. Energy Policy, 47, 416-423.

Garg, A. K., \& Rijst, J. (2015). The benefits and pitfalls of employees working from home: Study of a private company in South Africa. Corporate Board: Role Duties \& Composition, 11(2), 36-49.

Gharaghooshi, F. Z., McMeel, D., \& Manfredini, M. (2014). Digital technologies and the production of spaces of resistance. In International Contemporary Urban Issues Conference on Rethinking the Informality. https://doi.org/10.13140/RG.2.1.3939.6089

Gibbs, M., Mengel, F., \& Siemroth, C. (2021). Work from home \& productivity: Evidence from personnel \& analytics data on IT professionals. BFI Working Paper no. 2021-56. Becker Friedman Institute for Economics at UChicago. https://bfi.uchicago.edu/wp-content/uploads/2021/05/BFI_WP_ 2021-56.pdf

Gillespie, A. (1992). Communications technologies and the future of the city. In M. Breheny (Ed.), Sustainable development and urban form (pp. 67-77). Pion.

Golden, T. D. (2006). Avoiding depletion in virtual work: Telework and the intervening impact of work exhaustion on commitment and turnover intentions. Journal of Vocational Behavior, 69, 176-187.

Graham, S. (1997). Cities in the real-time age: Telecommunications as a paradigm challenge to the conception and planning of urban space. Environment and Planning A, 29, 105-127.

Graham, S. (1998). The end of geography or the explosion of place? Conceptualizing space place and information technology. Progress in Human Geography, 22(2), 165-185.

Graham, S., \& Marvin, S. (1996). Telecommunications and the city: Electronic spaces urban places. Routledge.

Graham, S., \& Marvin, S. (2001). Splintering urbanism: Networked infrastructures technological mobilities and the urban condition. Routledge.

Graham, M., \& Zook, M. (2011). Visualizing global cyberscapes: Mapping user-generated placemarks. Journal of Urban Technology, 18(1), 115-132.

Greear, J. P. (2015). Decentralized production and affective economies: Theorizing the ecological implications of localism. Environmental Humanities, 7, 107-127.

Gupta, P., \& Virwani, K. (2020). Co-working has cradled India's start-up boom - The support it now seeks is well deserved. Times of India Blog. https://timesofindia.indiatimes.com/blogs/voices/coworking-has-cradled-indias-start-up-boom-the-support-it-now-seeks-is-well-deserved/

Gusain, A. R. (2020). Work from home to work from anywhere - The future of co-working spaces. Article in ORF Digital Frontiers. https://www.orfonline.org/expert-speak/work-home-anywhere-futurecoworking-spaces/

Haraway, D. (1991). A manifesto for cyborgs: Science technology and socialist-feminism in the late twentieth century. In D. Haraway (Ed.), Simians cyborgs and women: The reinvention of nature (pp. 149-181). Routledge.

Harvey, D. (1989). The condition of postmodernity: An enquiry into the origins of cultural change. Blackwell.

Latour, B. (1993). We have never been modern. Harvester Wheatsheaf.

Liaw, G., Liang, S., \& Wang, Y. (2007). Relationships between critical factors associated with virtual work and virtual worker's organizational identification. Fu Jen Management Review, 15(1), 105-136.

Maslow, A. H. (1943). A theory of human motivation. Psychological Review, 50(4), 370-396.

Miller, H. J. (2017). Time geography and space-time prism. In D. Richardson, et al. (Eds.), The international encyclopedia of geography. Hoboken: John Wiley and Sons Ltd.

Moss, M. (1986). Telecommunications world cities and urban policy. Urban Studies, 24, 534-546.

Murray, S. (2008). Cybernated aesthetics: Lee Bull and the body transfigured. Performing Arts Journal, 30, 38-65.

Mütterlein, J., \& Fuchs, C. (2019). Digital technologies and their influence on spaces. Conference Paper at Twenty-third Pacific Asia Conference on Information Systems (PACIS), China. https://www. researchgate.net/publication/337818199_Digital_Technologies_and_their_Influence_on_Spaces

Negroponte, N. (1995). Being digital. Vintage Books.

Pawley, M. (1995). Architecture, urbanism and the new media. Mimeo. From Graham, S. (1998). The end of geography or the explosion of place? Conceptualizing space, place and information technology. Progress in Human Geography, 22(2), 165-185. https://doi.org/10.1191/030913298671334137

Robertson, R. (1995). Glocalization: Time-space and homogeneity-heterogeneity. In M. Featherstone, S. Lash, \& R. Robertson (Eds.), Global Modernities (pp. 25-44). Sage. 
Rose, G., Degen, M., \& Melhuish, C. (2014). Networks, interfaces, and computer-generated images: Learning from digital visualisations of urban redevelopment projects. Environment and Planning A, 32, 386-403.

Roudometof, V. (2016). Theorizing glocalization: Three interpretations. European Journal of Social Theory, 19(3), 391-408.

Ruiz, Y., \& Walling, A. (2005). Home-based working using communication technologies. Labour Market Trends, 113(10), 417-426.

Santos, I. N., \& Azevedo, J. (2019). Space-time compression and hyperlocalisation: The new flâneurs. Comunicação e Sociedade, 35, 259-277.

SAP Concur India Report. (2020). 88\% of Indian work force prefer to have the flexibility of working from home. https://www.concur.co.in/newsroom/article/88-of-indian-workforce-prefer-to-have-theflexibility-of-working-from

Slevin, J. (2000). The internet and society. Polity Press.

Senz, K. (2020). How much will remote work continue after the pandemic? HBS Working Paper in Working Knowledge - Business Research for Business Leaders, Harvard Business School. https:// hbswk.hbs.edu/item/how-much-will-remote-work-continue-after-the-pandemic

Stanton, C., Cullen, Z., Luca, M., Glaeser, E. L., \& Bartik, A. (2020). What jobs are being done at home during the COVID-19 crisis? Evidence from firm-level surveys. NBER Working Paper Series 27422. Cambridge, MA: National Bureau of Economic Research.

Sui, D., \& Morrill, R. (2004). Computers and geography: From automated geography to digital earth. In S. D. Brunn, S. L. Cutter, \& J. W. Harrington (Eds.), Geography and technology (pp. 81-108). Springer.

Swink, D. R. (2008). Telecommuter law: A new frontier in legal liability. American Business Law, 38(4), $857-900$.

Taneja, S., Mizen, P., \& Bloom, N. (2021). How has working from home impacted productivity? This UK survey has answers. World Economic Forum in collaboration with VoxEU. https://voxeu.org/article/ working-home-revolutionising-uk-labour-market

The Economist. (1995). Telecommunications survey, 30 September - 6 October. From Graham, S. (1998). The end of geography or the explosion of place? Conceptualizing space, place and information technology. Progress in Human Geography, 22(2), 165-185. https://doi.org/10.1191/ 030913298671334137

Thorstensson, E. (2020). The influence of working from home on employees' productivity - Comparative document analysis between the years 2000 and 2019-2020. Karlstad University.

Thrift, N. (1996). New urban eras and old technological fears: Reconfiguring the goodwill of electronic things. Urban Studies, 33, 1463-1493.

Thrift, N., \& French, S. (2002). The automatic production of space. Transactions of the Institute of British Geographers, 27(3), 309-335.

Tietze, S. (2002). When "work" comes "home": Coping strategies of teleworkers and their families. Journal of Business Ethics, 41(4), 385-396.

Tillema, T., Dijst, M., \& Schwanen, T. (2010). Face-to-face and electronic communications in maintaining social networks: The influence of geographical and relational distance and of information content. New Media \& Society, 12(6), 965-983.

van Dijk, J. A. G. M. (2006). The network society: Social aspects of new media. Sage.

Virilio, P. (1993). The third interval: A critical transition. In V. Andermatt-Conley (Ed.), Rethinking technologies (pp. 3-10). University Of Minnesota Press.

Wilson, M. W. (2012). Location-based services conspicuous mobility and the location-aware future. Geoforum, 43, 1266-1275.

Publisher's Note Springer Nature remains neutral with regard to jurisdictional claims in published maps and institutional affiliations. 